\title{
Targeting estrogen receptor beta (ER $\beta)$ for treatment of ovarian cancer: importance of KDM6B and SIRT1 for ER $\beta$ expression and functionality
}

\author{
Giulia Pinton', Stefan Nilsson ${ }^{2}$ and Laura Moro ${ }^{1}$
}

\begin{abstract}
Estrogen receptor (ER) $\beta$ has growth inhibitory and chemo drug potentiating effect on ovarian cancer cells. We studied the dependence of ER $\beta$ function on the presence of KDM6B and SIRT1 in human ovarian cancer cells in vitro. Activation of ERß with the subtype-selective agonist KB9520 resulted in significant inhibition of human ovarian cancer cell growth. KB9520-activated ERß had an additive effect on growth inhibition in combination with cisplatin and paclitaxel, respectively. Loss of KDM6B expression had a negative effect on ER $\beta$ function as a ligand-dependent inhibitor of ovarian cancer cell growth. In contrast, loss or inhibition of SIRT1 deacetylase activity restored ligandactivated ER $\beta$ functionality. Presented data suggest that selective targeting of ER $\beta$ with an agonist potentiate chemotherapy efficacy for the treatment of ovarian cancer and that downregulation or inhibition of SIRT1 may further enhance its therapeutic effect.
\end{abstract}

\section{Introduction}

Ovarian epithelial carcinoma (OEC), believed to originate from the ovarian surface epithelium, is the fourth commonest cause of female cancer death in the developed world. The OEC incidence is estimated to more than 240,000 new cases and around 150,000 deaths per year worldwide. The highest rates are reported in Scandinavia, Eastern Europe, USA, and Canada ${ }^{1-4}$.

The etiology of OEC is poorly understood but it is believed that nulliparity, high plasma levels of estrogen or long-term estrogen replacement therapy increases the risk for ovarian cancer, whereas pregnancy, lactation, and oral contraceptives decrease the risk ${ }^{1,4-7}$.

The standard of care for the management of advanced ovarian cancer has been unchanged for many years and

\footnotetext{
Correspondence: Laura Moro (laura.moro@uniupo.it)

${ }^{1}$ Department of Pharmaceutical Sciences, University of Piemonte Orientale "A Avogadro", 28100 Novara, Italy

²Department of Biosciences and Nutrition, Karolinska Institutet, S-141 57

Huddinge, Sweden
}

includes maximum cytoreductive surgery followed by platinum-based chemotherapy (carboplatin or cisplatin) in combination with paclitaxel ${ }^{2,8}$. Although the response rate for first-line carboplatin and paclitaxel is high, approximately $80 \%$ of patients with advanced OEC will experience recurrence and eventually become resistant to chemotherapy ${ }^{2,8}, 9$. New investigational drugs targeting different pathways for improved disease control and for the treatment of platinum-resistant OEC are emerging ${ }^{10}$.

Both estrogen receptor (ER) subtypes, ER $\alpha$ and $E R \beta$, are expressed in normal ovarian tissue as well as in ovarian cancer cells ${ }^{7,11}$. There is, however, a falling trend in ER $\beta$ expression as cells transition from normal to malignant state and with a further decline in its expression as the malignancy develops from early (stage I) to late disease stages (stage II-IV). No such trend in the expression of $E R \alpha$ has been observed ${ }^{7}, 11$.

The levels of ER $\alpha$ are closely associated with estrogendependent growth and to increased metastatic potential of OEC by promoting epithelial-mesenchymal transition 
(EMT) through upregulation of Snail and Slug and downregulation of E-cadherin. In contrast, ER $\beta$ mediates opposite effects to ER $\alpha$ in the presence of $17 \beta$-Estradiol (E2), resulting in inhibition of EMT ${ }^{12}$.

Although $40-60 \%$ of ovarian cancers express ER $\alpha$, only a portion (15-18\%) of them benefit from anti-estrogen (SERM) treatment, if at all. Tamoxifen produces only a modest effect in ovarian cancer ${ }^{1,11,13}$.

Introduction of ER $\beta$ into the ER $\alpha$-positive human epithelial ovarian cancer cell line BG-1 led to decreased basal and E2-induced cell proliferation in vitro. Moreover, ER $\beta$ expression resulted in downregulation and inhibition of $E R \alpha$ activity, arrested the cells in the G2/M phase, and decreased the pAKT levels ${ }^{13}$.

Treatment of the ovarian cancer cell lines SKOV3 and OV2008 with the ER $\alpha$-selective agonist, PPT, led to a significant stimulation of cell growth. In contrast, the ER $\beta$-selective agonist, DPN, significantly suppressed the growth of the two ovarian cancer cells. Moreover, the size of tumors in the in vivo SKOV3 xenograft model were significantly smaller in DPN-treated compared to vehicletreated animals ${ }^{14}$. A recent study provided evidence that also natural ER $\beta$ agonists have the potential to reduce cell viability and survival and to promote apoptosis of OEC cells ${ }^{15}$.

ER $\beta$ expression in ovarian cancer cells has been found to be significantly associated with longer disease-free survival and overall survival $(\mathrm{OS})^{11}$. Moreover, patients with more than $30 \%$ of ER $\beta$-positive cancer cells were shown to respond well to chemotherapy and with increased progression-free survival and OS compared to patients with less than $30 \%$ of ER $\beta$-positive tumor cells ${ }^{1}$. The analysis also demonstrated significantly longer OS time of patients with higher ER $\beta$ immunoreactivity score after chemotherapy, compared with patients with low ER $\beta$ score.

The recent discovery of alterations in genes encoding histone modifiers suggests their possible roles in cancer development. The lysine-specific demethylase 6B (KDM6B), also called Jumonji domain-containing protein D3 (Jmjd3), is a member of the family of JmjC histone demethylases that specifically catalyzes the demethylation of di-methylated or tri-methylated Lys 27 in histone H3 (H3K27me2/3). The role of KDM6B has been extensively studied in development, cell plasticity, immune system, neurodegenerative disease, and cancer ${ }^{16}$.

While, H3K27me3 is considered a repressive epigenetic mark and is recognized as a determining factor in promoting tumorigenesis and tumor progression, the mechanisms underlying KDM6B expression and function in cancer is still controversial ${ }^{17}$.

Accumulating evidence indicates that SIRT1, involved in a variety of cellular processes, is a key player in oncogenesis and cancer progression. SIRT1 belongs to a family of seven class III histone deacetylases (HDACs) enzymes, which are highly conserved enzyme homologs of the yeast Sir2 protein, with nicotine adenine dinucleotide NAD +-dependent protein deacetylase activity ${ }^{18}$. Overexpression of SIRT1 has been recently associated with poor outcome and chemoresistance of OEC patients ${ }^{19-22}$.

In this report we have studied the role and effect of ER $\alpha$ and ER $\beta$ in response to the natural hormone estradiol (E2) and the subtype-selective agonists PPT (ER $\alpha$-selective) and KB9520 (ER $\beta$-selective) in the human ovarian cancer cell lines SKOV3 and A2780cis. Furthermore, we have characterized the role of KDM6B and SIRT1 for the tumor inhibitory mechanism of ER $\beta$ in the presence of its selective agonist KB9520.

Altogether, the preclinical and clinical data on OEC suggest that selective targeting of ER $\beta$ may provide a significant improvement of existing therapy for the treatment of ovarian cancer, at least for the patient population that expresses ER $\beta$.

\section{Results}

\section{ER subtype expression and response to ligands}

The expression of the two ER subtypes, ER $\alpha$ and ER $\beta$, was investigated in the human ovarian cancer cell lines SKOV3 and A2780cis, respectively. The SKOV3 cells were shown to express both ER subtypes at gene and protein levels, whereas the A2780cis cells only expressed ER $\beta$ (Fig. 1a). The effect of the non-subtype-selective agonist E2 and the two ER subtype-selective ligands KB9520 and PPT on cell growth was explored (Fig. 1b, c). The ER $\beta$ selective agonist KB9520 resulted in a robust, concentration-dependent, inhibition of cell growth of both SKOV3 and A2780cis cells, with a maximum at 5-10 nM. The ER $\alpha$-selective agonist PPT caused only a weak concentration-dependent stimulation of SKOV3 cell growth, whereas the growth of the ER $\alpha$-negative A2780cis cells was unaffected. E2 inhibited the growth of A2780cis cells in a concentration-dependent fashion, and unexpectedly, of also SKOV3 cells, with a similar efficacy as the ER $\beta$-selective agonist KB9520. This efficacious and unexpected cell growth inhibitory effect of E2 in the SKOV3 cells may, however, be explained by the reported loss-of-function mutation of ER $\alpha$ in these cells ${ }^{23}$. Because of the mutated ER $\alpha$ in SKOV3 cells, we transfected A2780cis cells with a wild-type ER $\alpha$ expression vector (Fig. 2a). As shown in Fig. 2b, PPT resulted in a robust stimulation of A2780cis/ER $\alpha$ cell growth as compared to SKOV3 cells (Fig. 1b), with maximum stimulation at a concentration of 5-10 nM. E2 still caused inhibition of cell growth, similar to that of KB9520, despite the expression of wild-type ER $\alpha$ (Fig. 2b). In combination with a fixed concentration of PPT ( $5 \mathrm{nM})$, KB9520 inhibited the growth stimulatory effect of PPT in a concentration-dependent fashion (Fig. 2c). Combination 


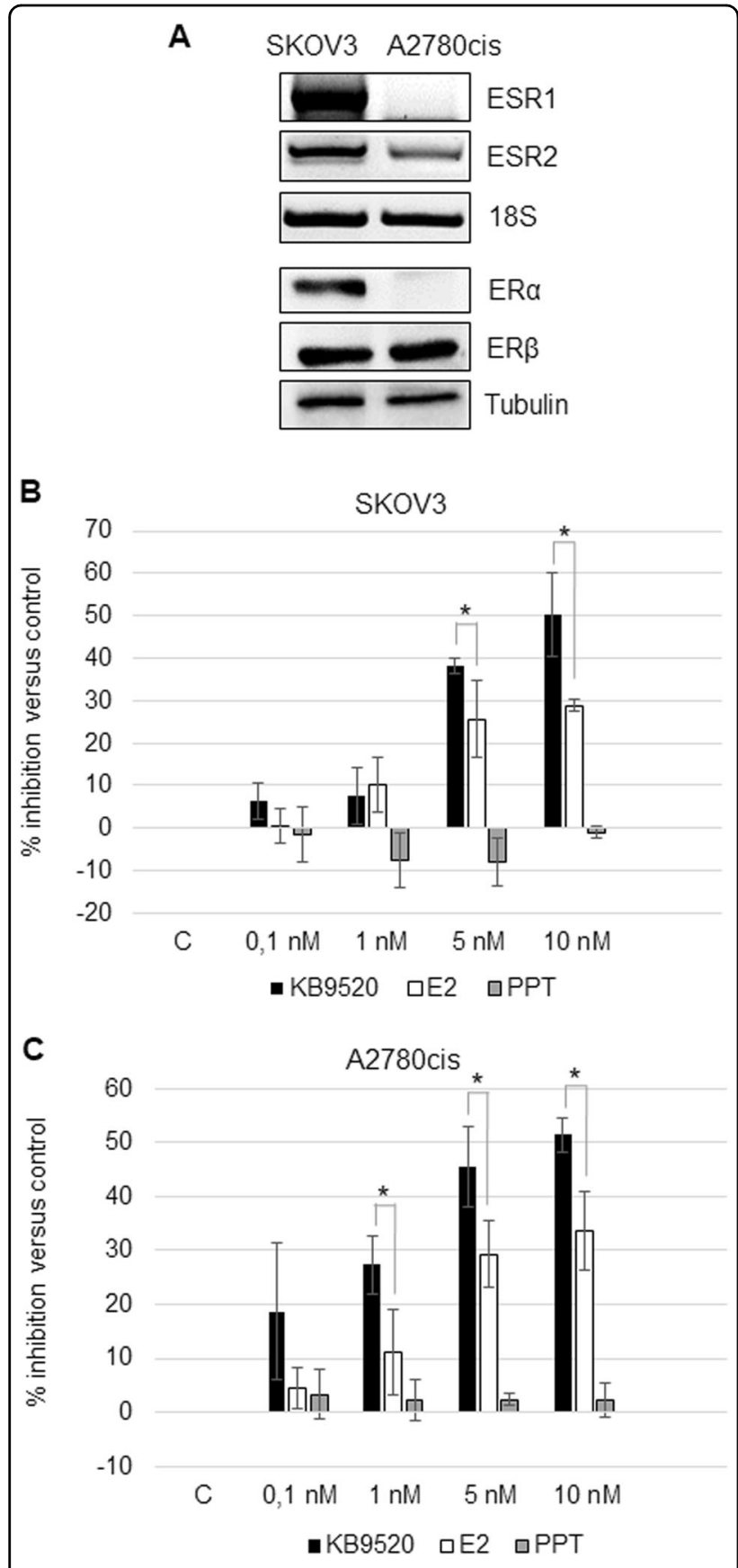

Fig. 1 Estrogen receptor subtype expression and response to ligands. a Representative RT-PCR and Western blot analyses of ESR1 and ESR2 expression in SKOV3 and A2780cis cells. 18S rRNA and

Tubulin were used as controls. b Percentage of growth inhibition in SKOV3 and c A2780cis cells after 24-h treatment with different doses of KB9520, E2, or PPT, in the range of 0.1 to $10 \mathrm{nM}$. Results are expressed as mean \pm s.d. of three independent experiments. ${ }^{*} p \leq 0.05$

of a fixed concentration of E2 with increasing concentrations of KB9520 resulted in an additive effect on cell growth inhibition.

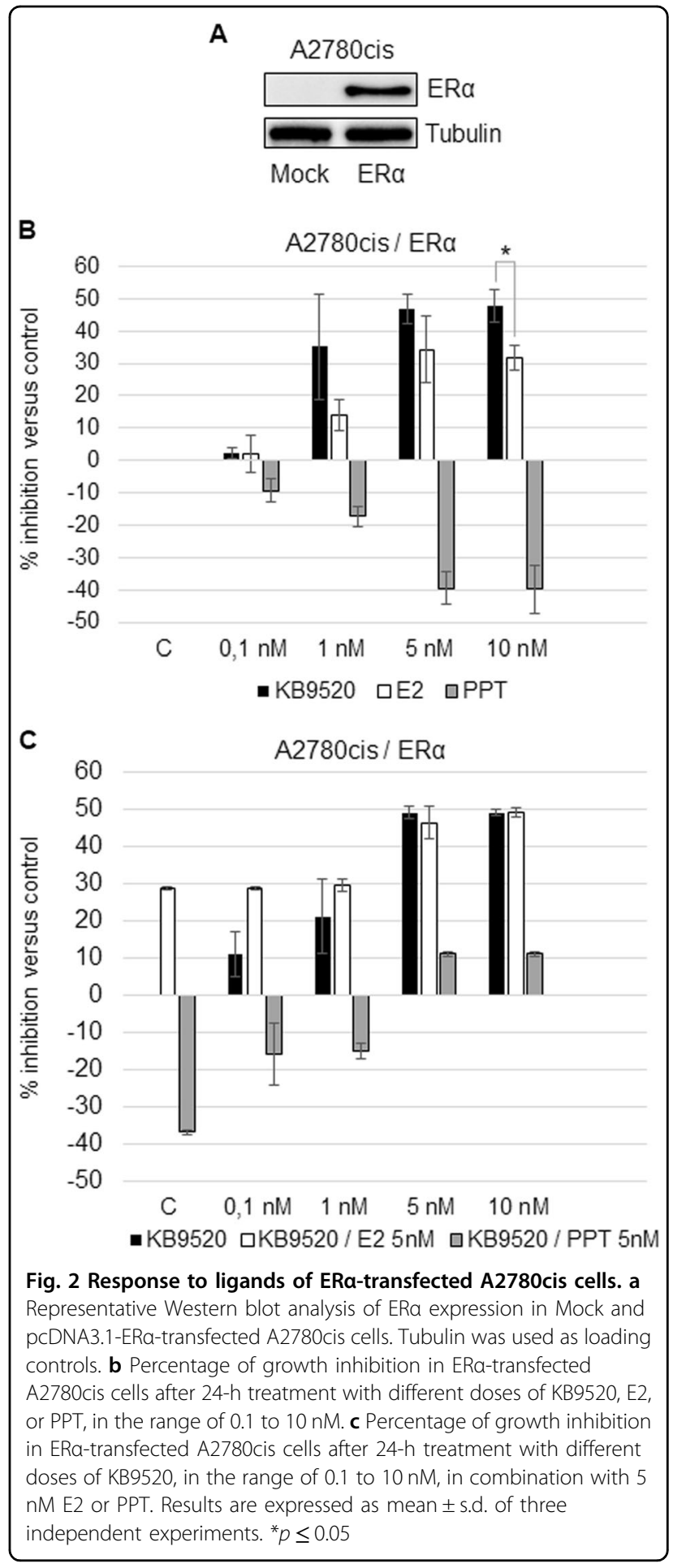

\section{Agonist-activated ER $\beta$ destabilizes the ERa protein}

It has previously been reported that ER $\beta$ has an inhibitory effect on ER $\alpha$ expression and activity in BG-1 epithelial ovarian cancer cells ${ }^{12,}{ }^{13}$. To explore the potential mechanism of the inhibitory effect of ER $\beta$ on $\mathrm{ER} \alpha$ activity in A2780cis cells, we treated the A2780cis/ 


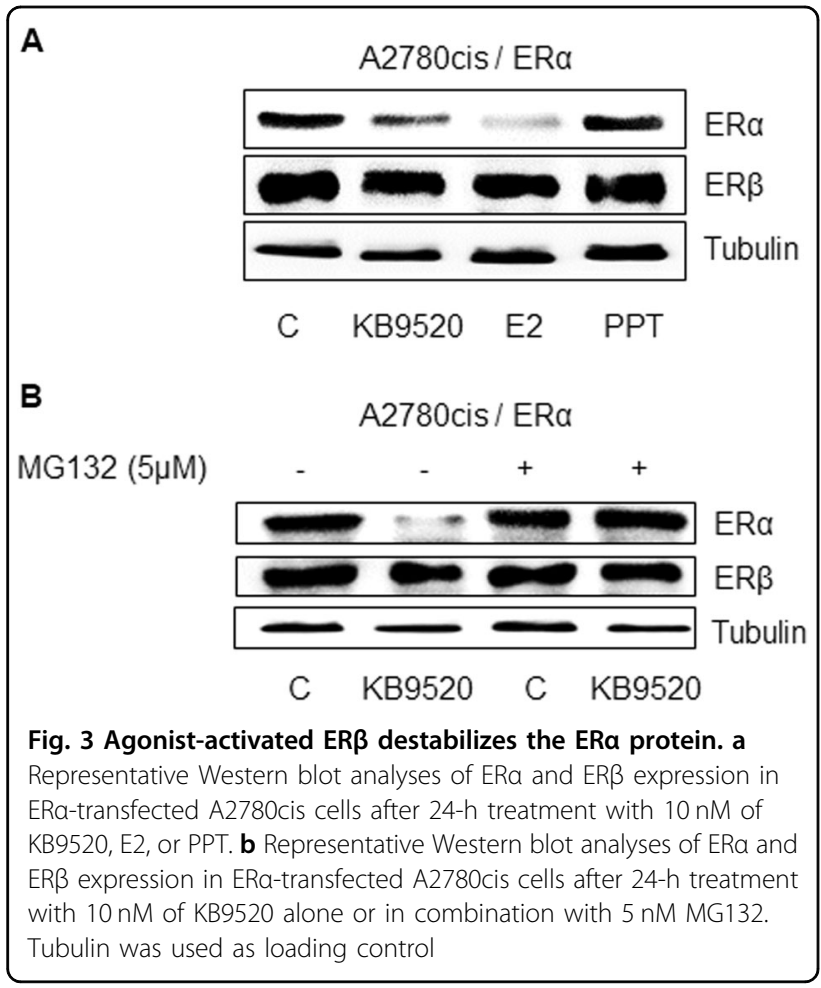

ER $\alpha$ cells with E2 and KB9520 for $24 \mathrm{~h}$. As shown in Fig. $3 \mathrm{a}$, the ER $\beta$-selective agonist KB9520 and the non-ER subtype-selective agonist E2 resulted in decreased ER $\alpha$ protein levels as compared to PPT and untreated A2780cis/ER $\alpha$ cells. To further investigate this effect of $E R \beta$ on $E R \alpha$ protein stability, the A2780cis/ER $\alpha$ cells were treated with KB9520 in the absence or presence of the proteasome inhibitor MG132 (Fig. 3b). Treatment with MG132 resulted in stabilization of the $\mathrm{ER} \alpha$ protein at control levels in the presence of KB9520, suggesting that ER $\beta$ plays a role in proteasome-mediated ER $\alpha$ protein degradation.

\section{Additive effect of KB9520 on cisplatin and paclitaxel sensitivity in A2780cis and SKOV3 cells}

The ER $\beta$-selective agonist KB9520 had a synergistic effect on cisplatin sensitivity in the malignant pleural mesothelioma REN cell line in vitro and in vivo ${ }^{24}$. In this study, treatment of A2780cis and SKOV3 cells with a fixed concentration of KB9520, on top of increasing concentrations of cisplatin, resulted in an additive effect over the full range of cisplatin concentrations (Fig. 4a, S1A, B), whereas PPT was without effect. Treatment with E2 also resulted in an additive effect in combination with cisplatin but less pronounced than KB9520 (data not shown). KB9520 treatment also increased the level of cleaved PARP1 in combination with cisplatin (Fig. 4b, c).
Additive growth inhibition of A2780cis cells was also observed when cells were treated with KB9520 in combination with paclitaxel (Fig. S2).

Role of KDM6B and SIRT1 for the expression and function of ER $\beta$ and its response to KB9520 in A2780cis cells

We have previously reported an important role for the Jumonji domain containing 3 histone demethylase KDM6B for the expression of ER $\beta$ in human epithelioid and biphasic pleural mesothelioma cell lines ${ }^{25}$. In this report we observed that KB9520-activated ER $\beta$ increased the levels of $K D M 6 B$ almost 20-fold, whereas the expression of the methyltransferase $E Z H 2$ was unaffected (Fig. S3). Knock-down of $K D M 6 B$ affected the function of $E R \beta$ as a ligand-dependent transcription factor. siRNA inhibited expression of $K D M 6 B$ resulted in increased expression of SIRT1, at both the mRNA and protein levels, and decreased transcripts of the ER $\beta$ gene (ESR2), with a subsequent consequence on the ER $\beta$ protein level (Fig. 5a, b). Whereas acetylation of ER $\beta$ and complex formation with p300 was increased in a KB9520dependent fashion in control cells (Fig. 5c), knock-down of KBM6B led to decreased acetylation of the ER $\beta$ protein and its complex formation with $\mathrm{p} 300$, irrespective of the presence or absence of KB9520 (Fig. 5d). In addition, the cellular sensitivity to cisplatin and the additive effect of KB9520 was lost (Fig. 5e, f, S4). Also the KB9520mediated inhibition of $S I R T 1$ expression was significantly reduced following knock-down of $K D M 6 B$ (Fig. 5g, h). KB9520 did not induce ER $\alpha$ acetylation and, in addition, led to reduced $\mathrm{p} 300: \mathrm{ER} \alpha$ association (Fig. S5).

Inhibition of SIRT1 expression led, on the other hand, to increased $K D M 6 B$ expression and increased levels of ER $\beta$ protein, without increased transcription of the ESR2 gene (Fig. 6a, b). Absence of SIRT1 expression and activity (by gene silencing or inhibition of protein catalytic activity by EX527) resulted in increased ligand-dependent acetylation of ER $\beta$ and re-association with acetylated p300 (Fig. 6c, S6A, B). Moreover, SIRT1 depletion restored sensitivity to KB9520 in combination with cisplatin (Fig. $6 \mathrm{~d}, \mathrm{e})$. To strengthen our suspicion that SIRT1 has a more direct role in the deacetylation of ER $\beta$, A2780cis cells were treated with and without KB9520 for a shorter time point than $2 \mathrm{~h}$. Cell extracts immunoprecipitated with a p300 antibody showed that SIRT1 exists in a complex with p300 and ER $\beta$ and that this association is ligand dependent (Fig. 6f).

\section{Discussion}

The standard of care for the management of advanced ovarian cancer has been unchanged for many years and includes maximum cytoreductive surgery followed by platinum-based chemotherapy (carboplatin or cisplatin) in combination with paclitaxel ${ }^{2,8}$. Although the response 


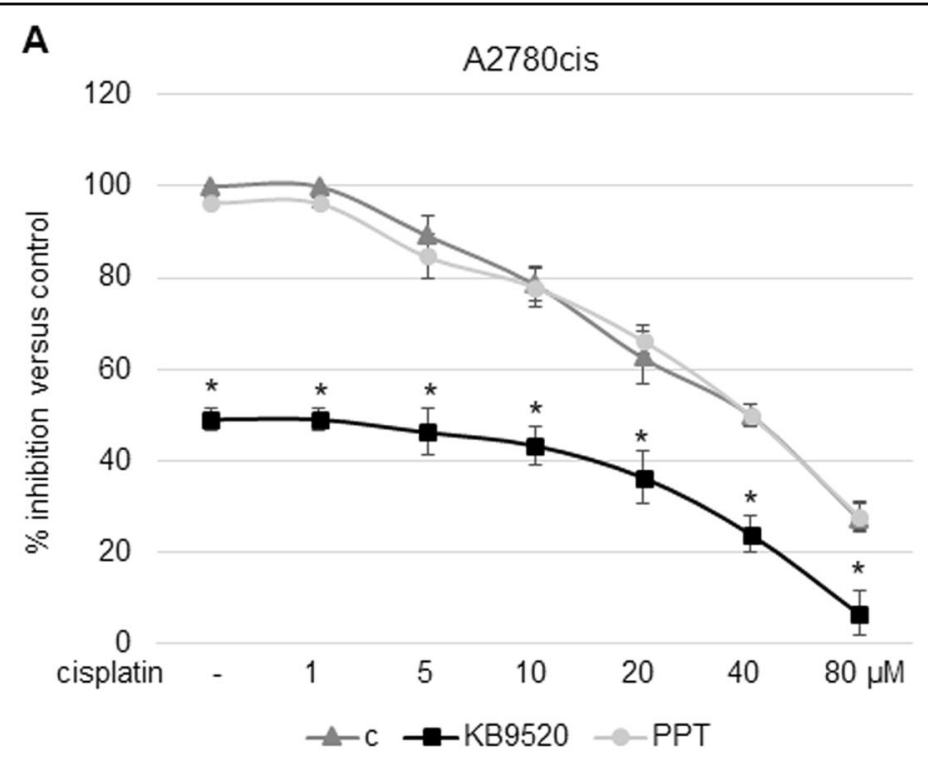

B

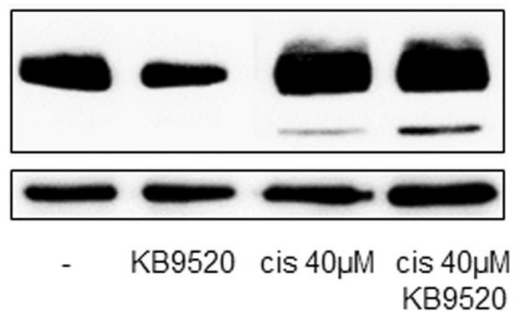

C

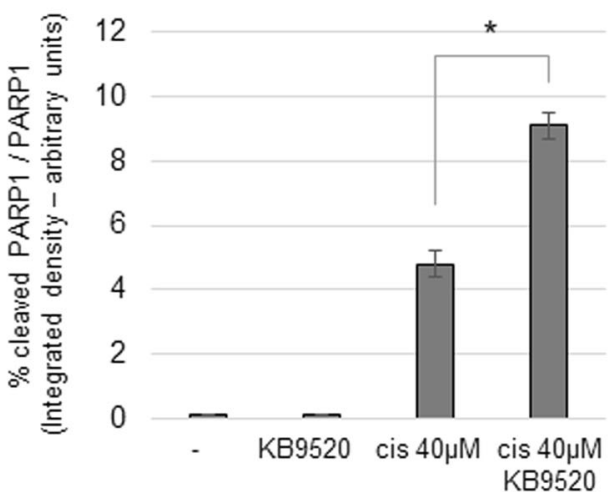

Fig. 4 Additive effect of KB9520 on cisplatin sensitivity in A2780cis cells. a Percentage of growth inhibition in A2780cis cells after 24-h treatment with different doses of cisplatin, in the range of 1 to $80 \mu \mathrm{M}$ alone or in combination with $10 \mathrm{nM}$ of KB9520 or PPT. Results are expressed as mean \pm s.d. of three independent experiments. ${ }^{*} p \leq 0.05$. b Representative Western blot and $\mathbf{c}$ densitometric analyses of PARP1 cleavage in A2780cis cells after $24-\mathrm{h}$ treatment with $40 \mu \mathrm{M}$ of cisplatin alone or in combination with $10 \mathrm{nM}$ of KB9520. * $p \leq 0.05$. Tubulin was used as loading control

rate for first-line carboplatin and paclitaxel is $70-80 \%$, the majority of women with advanced ovarian cancer will relapse or progress and eventually develop chemotherapyresistant disease ${ }^{2,}{ }^{9}$. Clinical trials in the search for innovative, targeted therapies for treatment of ovarian cancer is ongoing but so far no standard second-line treatment stands out as superior with regard to efficacy or safety.

It has previously been reported that ER $\beta$ mediates ovarian cancer cell growth repression by decreasing the cellular content of, among others, retinoblastoma, phospho-AKT, cyclin D1, and A2 as well as upregulating the cyclin-dependent kinase inhibitor $\mathrm{p} 21^{13,14,26,27}$. In this report we have focused on other aspects of ER $\beta$ function and activity as a ligand-activated transcription factor and growth inhibitor of tumor cells.
We initiated the studies on the human ovarian cancer cell lines, SKOV3 and A2780cis, by determining their expression of $E R \alpha$ and $E R \beta$, respectively, and by exploring the effect of the non-subtype-selective, natural hormone E2, which binds to ER $\alpha$ and ER $\beta$ with similar affinity, and the two subtype-selective agonists KB9520 (ER $\beta$-selective) and PPT (ER $\alpha$-selective), on the growth of these cells (Fig. $1)$. In the presence of both ER subtypes, we could show that KB9520 had a dominant inhibitory effect on cell growth, antagonizing the growth stimulatory effect of PPT (Fig. 2), which is in agreement with published results on DPN and PPT on the mouse mammary cell line $\mathrm{HC}_{1}{ }^{28}$. Perhaps less expected was that E2 also exerted a dominant cell growth inhibition, with the same efficacy as KB9520, despite the presence of also ER $\alpha$ (Fig. 2). This result is in disagreement with published results on the mouse 
A

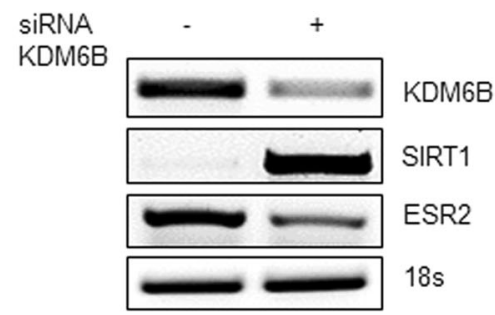

C

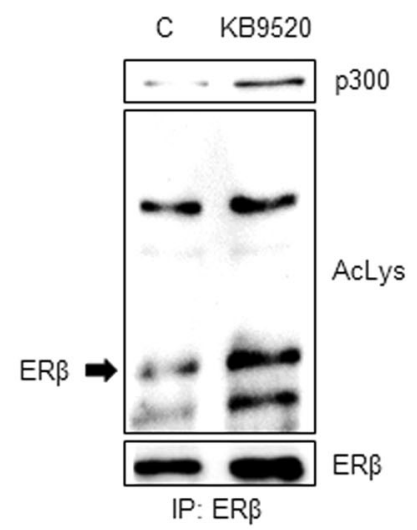

E

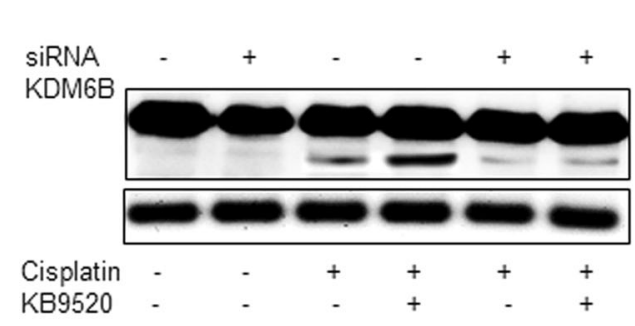
KB9520

G

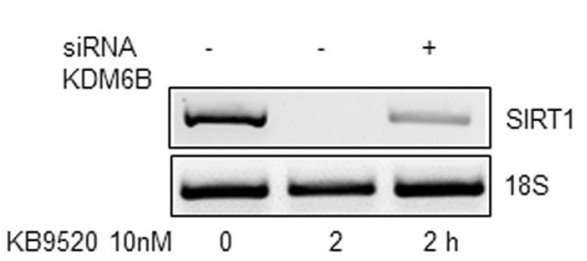

B

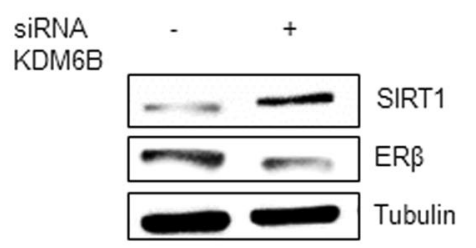

D

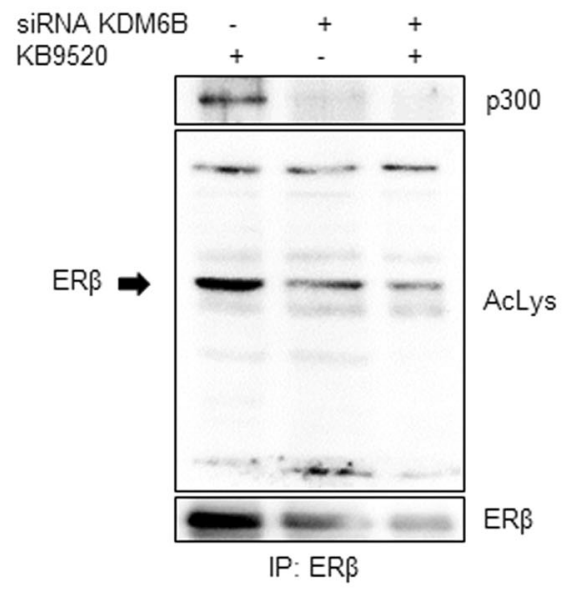

$\mathbf{F}$

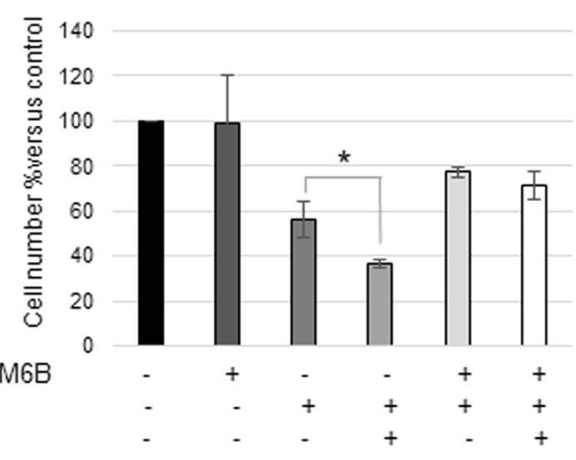

H

$400 \quad$ SIRT1

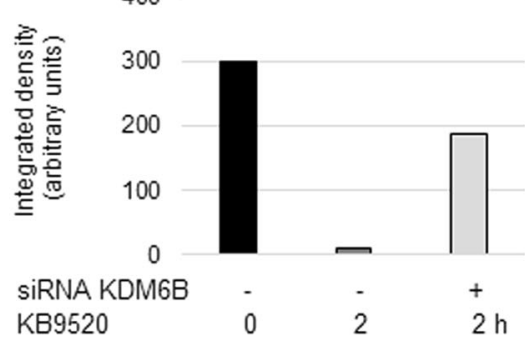

Fig. 5 (See legend on next page.) 


\begin{abstract}
Fig. 5 Role of KDM6B for the expression and function of ER $\boldsymbol{\beta}$ and its response to KB9520 in A2780cis cells. a Representative RT-PCR and $\mathbf{b}$ Western blot analyses of KDM6B, SIRT1, and ESR2 expression in A2780cis cells transfected $48 \mathrm{~h}$ with non-specific or KDM6B-specific siRNAs. 18S rRNA and Tubulin were used as controls. c Immunoprecipitation of ER 3 , from lysates of A2780cis cells treated or not with 10 nM of KB9520, 2 h; lysine acetylation and co-immunoprecipitated proteins were detected by Western blot analyses using the respective antibodies (AcLys, ERR, and p300). $\mathbf{d}$ Immunoprecipitation of ERB, from lysates of A2780cis cells transfected $48 \mathrm{~h}$ with non-specific or KDM6B-specific siRNAs and treated or not with $10 \mathrm{nM}$ of KB9520, 2 h; lysine acetylation and co-immunoprecipitated proteins were detected by Western blot analyses using the respective antibodies (AcLys, ERB, and p300). e Representative Western blot analysis of PARP1 cleavage in A2780cis cells transfected with non-specific or KDM6B-specific siRNAs after $24 \mathrm{~h}$ treatment with $40 \mu \mathrm{M}$ of cisplatin alone or in combination with $10 \mathrm{nM}$ of KB9520. Tubulin was used as loading control. $\mathbf{f}$ Percentage of viable A2780cis cells transfected with non-specific or KDM6B-specific siRNAs after $24 \mathrm{~h}$ treatment with $40 \mathrm{\mu M}$ of cisplatin alone or in combination with $10 \mathrm{nM}$ of KB9520. Results are expressed as mean \pm s.d. of three independent experiments. ${ }^{*} p \leq 0.05$. $\mathbf{g}$ Representative RT-PCR, and $\mathbf{h}$ respective densitometry, of SIRT1 expression in A2780cis cells transfected with non-specific or KDM6B-specific siRNAs for $48 \mathrm{~h}$ and then treated or not with 10 nM of KB9520 for $2 \mathrm{~h}$. $18 \mathrm{~S}$ rRNA was used as housekeeping gene
\end{abstract}

mammary cell line $\mathrm{HC}_{1}{ }^{28}$. This discrepancy may, however, be due to the difference in origin of the cell lines since our E2 results are in agreement with published data in ER $\beta$ overexpressed, human ovarian, and breast cancer cell lines that express endogenous ER $\alpha$; ER $\beta$ has a dominant, negative influence on ER $\alpha$ activity ${ }^{12,13,29,30}$.

That the proteasome inhibitor MG132 prevented loss of the $E R \alpha$ protein, following activation of $E R \beta$ with KB9520, suggests that $E R \beta$ is responsible for targeting $E R \alpha$ for proteasome pathway degradation (Fig. 3a, b).

Due to the ER $\beta$-mediated loss of the ER $\alpha$ protein, presented data strongly support our notion that the growth inhibition by E2, in the presence of both ER subtypes, is mediated by ER $\beta$. However, also other mechanisms may explain the dominant growth inhibitory effect of ER $\beta$ such as: formation of $E R \alpha: E R \beta$ heterodimer in the presence of $\mathrm{E} 2$ and that ER $\beta$ dictates the activity of the heterodimer, competition with ER $\alpha$ for binding to sites on DNA within target genes or competition for interaction with coregulatory proteins (Fig. S5) ${ }^{29-31}$.

Although we received a similar increase in cleaved PARP1 by KB9520 in combination with cisplatin in the A2780cis cells as in the human malignant pleural REN cell line, we did not observe a synergistic effect of cell growth inhibition (Fig. 4, S1) ${ }^{24}$. The mechanistic difference in response, additive vs. synergism, is unknown to us and needs further and deeper investigation.

Posttranslational acetylation of ER $\alpha$ was recently reported to play an important role for its activity as a ligand-activated transcription factor ${ }^{32}$ and for its stability $^{33}$. In this study we can for the first time present data showing that also acetylation of ER $\beta$ is important for its function as a ligand-dependent regulator of cellular events (Figs. 5, 6).

That KDM6B is important for ER $\beta$ expression was previously reported by us ${ }^{25}$. In this report, we show that KDM6B is also important for ER $\beta$ function. Liganddependent acetylation of ER $\beta$ and its interaction with p300 was lost following depletion of KDM6B (Fig. 5c compared to $5 \mathrm{~d})$. Moreover, the ligand-dependent, additive effect of ER $\beta$ on PARP1 cleavage in combination with cisplatin vanished (Fig. 5e, f) and the ability of $E R \beta$ to downregulate SIRT1 expression in a ligand-dependent fashion was lost (Fig. 5g, h). Whether the transcriptional regulation of the SIRT1 gene by ligand-activated ER $\beta$ is direct or indirect through KDM6B needs further studies; KB9520-activated ER $\beta$ upregulated KDM6B expression approximately 20 -fold (Fig. S3).

SIRT1 was found to exist in a complex with ER $\beta$ and p300 at the $1 \mathrm{~h}$ time point but not at $2 \mathrm{~h}$ or later, implying that deacetylation of ER $\beta$ is a sequential event (Fig. 6e compared to $6 \mathrm{c}$ and S6). We speculate that loss of ER $\beta$ acetylation follows SIRT1-mediated deacetylation of lysine residues 1020/1024 within the cell cycle regulatory domain 1 of $\mathrm{p} 300$, which thereafter results in reduced p300-mediated ER $\beta$ acetylation ${ }^{32-35}$.

Loss of ER $\beta$ acetylation and thereby ligand-dependent ER $\beta$ function may be due to decreased DNA-binding activity, inability to interact with coregulators for negative or positive transcriptional gene regulation, changed subcellular location or decreased binding affinity for KB9520 32 .

Knock-down of SIRT1 caused increased levels of ER $\beta$ protein without increased transcription of the ESR2 gene. The mechanism for this effect is unclear but may be a result of a stabilized ER $\beta$ protein when acetylated.

Which lysine residues in ER $\beta$ that are targets for acetylation need further studies. In conclusion, in this report, we have provided data showing that the function and ligand-dependent activity of ER $\beta$, as an ovarian tumor cell growth inhibitor, is dependent of posttranslational acetylation and that the level of KDM6B and the NAD +-dependent deacetylase SIRT1 play important roles in this process. We have also demonstrated that selective activation of ER $\beta$ is additive to cisplatin and paclitaxel in the inhibition of ovarian tumor cell growth and that ER $\beta$ has a dominant cell regulatory effect over $\mathrm{ER} \alpha$, even in the presence of E2. Moreover, we have shown that KB9520activated ER $\beta$ has a strong stimulatory effect on KDM6B expression, that most likely add to the ER $\beta$-mediated 


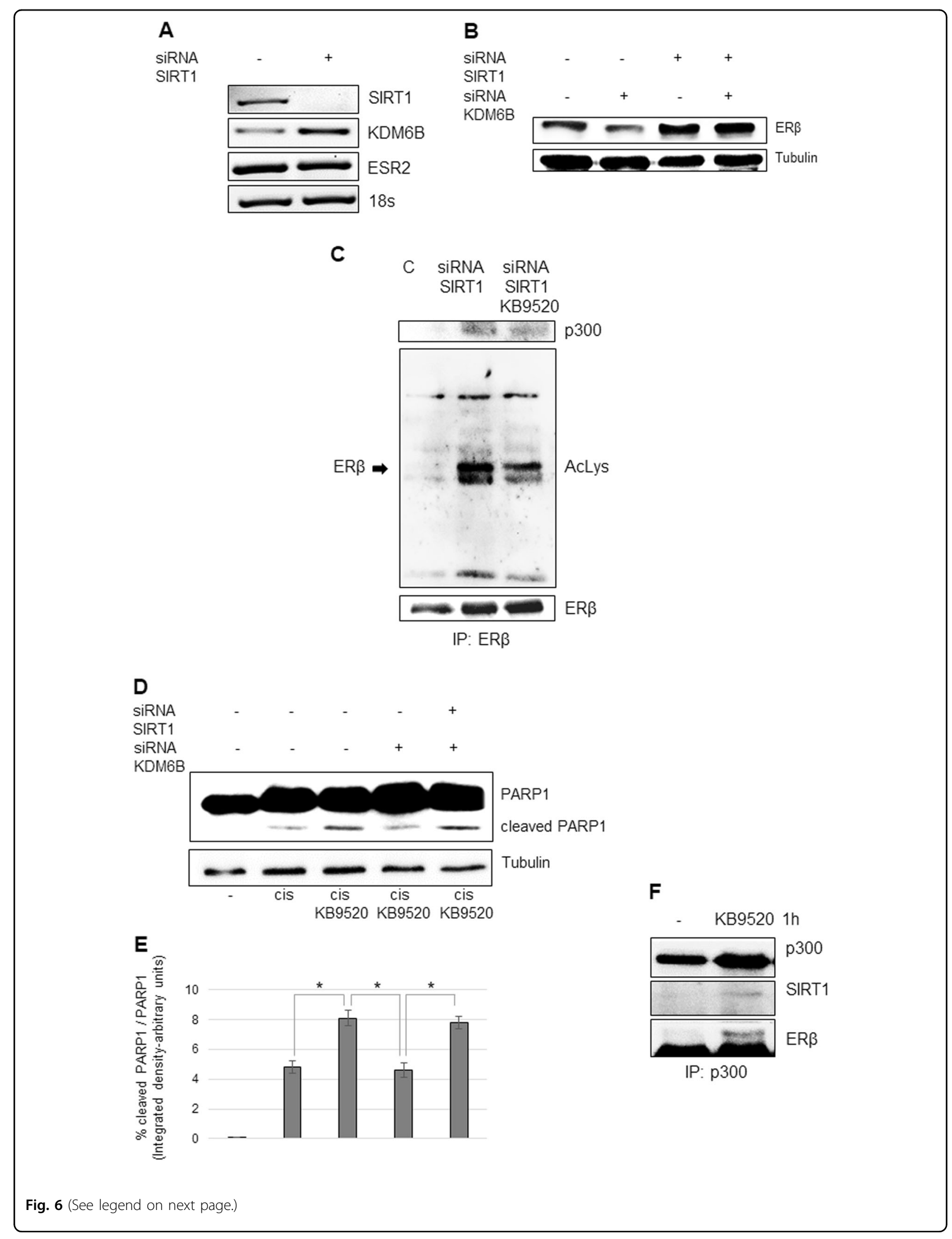


Fig. 6 Role of SIRT1 for the expression and function of ER $\boldsymbol{\beta}$ and its response to KB9520 in A2780cis cells. a Representative RT-PCR of SIRT1, $K D M 6 B$, and ESR2 expression and $\mathbf{b}$ Western blot analyses of ER $\beta$ expression in A2780cis cells transfected with non-specific or SIRT1 and KDM6Bspecific siRNAs. $18 \mathrm{~S}$ rRNA and Tubulin were used as controls. c Immunoprecipitation of ERß, from lysates of A2780cis cells transfected for $48 \mathrm{~h}$ with non-specific or SIRT1-specific siRNAs and then treated or not with $10 \mathrm{nM}$ of KB9520, $2 \mathrm{~h}$; lysine acetylation and co-immunoprecipitated proteins were detected by Western blot analyses using the respective antibodies (AcLys, ERß, and p300). $\mathbf{d}$ Representative Western blot and e densitometric analysis of PARP1 cleavage in A2780cis cells transfected with non-specific or SIRT1 and KDM6B-specific siRNAs after $24 \mathrm{~h}$ treatment with $40 \mu \mathrm{M}$ of cisplatin alone or in combination with $10 \mathrm{nM}$ of KB9520. Tubulin was used as loading control. ${ }^{*} p \leq 0.05$. $\mathbf{f}$ Immunoprecipitation of $p 300$, from lysates of A2780cis treated or not $1 \mathrm{~h}$ with $10 \mathrm{nM}$ of KB9520; co-immunoprecipitated proteins were detected by Western blot analyses using the respective antibodies (p300, SIRT1, and ERß)

ovarian tumor inhibitory activity. In summary, presented data suggest that selective targeting of ER $\beta$ with an agonist potentiate chemotherapy efficacy for the treatment of ovarian cancer and that downregulation or inhibition of SIRT1 may further enhance its therapeutic effect.

\section{Materials and methods \\ Reagents and antibodies}

The polyclonal antibodies specific for $\mathrm{ER} \alpha(\mathrm{H}-184), \mathrm{ER} \beta$ (H-150), SIRT1, p300 and the monoclonal antibodies specific for PARP1, acetylated-lysine, and $\alpha$-tubulin were purchased from Santa Cruz Biotechnology (Santa Cruz, CA, USA). Anti-mouse and anti-rabbit IgG peroxidase or FITC-conjugated antibodies, the proteasome inhibitor MG132, the selective SIRT1 inhibitor EX527 and chemical reagents were from Sigma-Aldrich (St Louis, MO, USA). ECL, nitrocellulose membranes, and protein assay kit were from Bio-Rad (Hercules, CA, USA). TRIzol, culture media, sera, and LipofectAMINE transfection reagent were from Thermo Fisher (Waltham, MA, USA). The ER $\alpha$-selective agonist PPT and $17 \beta$-estradiol were from Tocris Bioscience (Bristol, UK). The ER $\beta$-selective agonist KB9520 was originally provided by Karo Bio AB (Huddinge, SE) ${ }^{24}$. Today this ligand is owned by Oasmia Pharmaceuticals AB (Uppsala, SE).

\section{Cell cultures and transfection}

The ovarian cancer SKOV3 and A2780cis cell lines were purchased from Sigma-Aldrich (St Louis, MO, USA). Cells were grown in standard conditions in RPMI medium supplemented with $10 \% \mathrm{FBS}, 100 \mu \mathrm{g} / \mathrm{ml}$ streptomycin, and $10 \mu \mathrm{g} / \mathrm{ml}$ penicillin at $37{ }^{\circ} \mathrm{C}$ in a humidified environment containing $5 \% \mathrm{CO}_{2}$. Mycoplasma infection was excluded by the use of Mycoplasma PlusTM PCR Primer Set kit from Stratagene (La Jolla, CA, USA). Cells grown to $80 \%$ confluence in tissue culture dishes were transiently transfected with the pcDNA3.1-ER $\alpha$ plasmid or with specific siRNAs from Qiagen (Hilden, Germany), using the LipofectAMINE reagent as described by the manufacturer.

\section{Proliferation assays}

Cells were seeded at a density of $10 \times 10^{4}$ cells/well in 6well plates in RPMI medium supplemented with $10 \%$ FBS, $100 \mu \mathrm{g} / \mathrm{ml}$ streptomycin, and $10 \mu \mathrm{g} / \mathrm{ml}$ penicillin and incubated overnight at $37^{\circ} \mathrm{C}$ in a humidified environment containing $5 \% \mathrm{CO}_{2}$ to allow adherence. Following treatment cells were trypsinized and stained with Trypan blue. The number of cells considered viable (unstained cells) was counted in a Bürker haemocytometer within 5 min after staining.

\section{Cell cycle analysis}

For cell cycle/apoptosis analysis, $5 \times 10^{5}$ cells were seeded in tissue culture plates and treated with $10 \mathrm{nM}$ KB9520, $40 \mu \mathrm{M}$ cisplatin, or the combination of the two drugs for $24 \mathrm{~h}$ at $37^{\circ} \mathrm{C}$ in a $5 \% \mathrm{CO}_{2}$ atmosphere. After incubation, detached and suspended cells were harvested in complete RPMI and centrifuged at $500 \times g$ for $10 \mathrm{~min}$. Pellets were washed with PBS, fixed in ice-cold $75 \%$ ethanol at $4{ }^{\circ} \mathrm{C}$, treated with $100 \mathrm{mg} / \mathrm{ml}$ RNAse A for $1 \mathrm{~h}$ at $37^{\circ} \mathrm{C}$, stained with $25 \mu \mathrm{g} / \mathrm{ml}$ propidium iodide and finally analyzed by using a flow cytometer FACS (Becton Dickinson, San Jose, CA, USA) and Modfit software (Verity Software House, Topsham, ME, USA).

\section{Cell lysis, immunoprecipitation, and immunoblot}

Cells were extracted with 1\% NP-40 lysis buffer (1\% NP40, $150 \mathrm{mM} \mathrm{NaCl}, 50 \mathrm{mM}$ Tris- $\mathrm{HCl}$ pH $8.5 \mathrm{mM}$ EDTA, $10 \mathrm{mM} \mathrm{NaF}, 10 \mathrm{mM} \mathrm{Na} \mathrm{P}_{2} \mathrm{O}_{7}, 0.4 \mathrm{mM} \mathrm{Na} \mathrm{VO}_{4}$ ) with freshly added protease inhibitors $(10 \mu \mathrm{g} / \mathrm{ml}$ leupeptin, 4 $\mu \mathrm{g} / \mathrm{ml}$ pepstatin, and $0.1 \mathrm{Unit} / \mathrm{ml}$ aprotinin). Lysates were centrifuged at $13,000 \times g$ for $10 \mathrm{~min}$ at $4{ }^{\circ} \mathrm{C}$ and the supernatants were collected and assayed for protein concentration with the Bio-Rad protein assay method. For immunoprecipitation experiments, $2 \mathrm{mg}$ of extracted protein for each treatment were incubated with specific antibodies for $1 \mathrm{~h}$ at $4{ }^{\circ} \mathrm{C}$ and $50 \mu \mathrm{l}$ protein A-Sepharose beads. Proteins were separated by SDS-PAGE under reducing conditions. Following SDS-PAGE, proteins were transferred to nitrocellulose, reacted with specific antibodies and then detected with peroxidase-conjugate secondary antibodies and chemioluminescent ECL reagent. Digital images were taken with the Bio-Rad 
ChemiDocTM Touch Imaging System and quantified using Bio-Rad Image Lab 5.2.1.

\section{RNA isolation and RT-PCR}

Total RNA was extracted using TRIzol reagent. Starting from equal amounts of RNA, cDNA used as template for amplification in the RT-PCR $(5 \mu \mathrm{g})$, was synthesized by the reverse transcription reaction using RevertAid Minus First Strand cDNA Synthesis Kit from Fermentas-Thermo Scientific (Burlington, ON, Canada), using random hexamers as primers, according to the manufacturer's instructions. $20 \mathrm{ng}$ of cDNA were used to perform RTPCR amplification.

The primers sequences were: ESR1, Fw 5'AACAAAGGCATGGAGCATCTGT- $3^{\prime}$ and Rev $5^{\prime}$ TGATGTAATACTTTTGCAAGG-3'; ESR2, Fw 5'GTCAGGCATGCGAGTAACAA-3' and Rev $5^{\prime}$ GGGAGCCCTCTTTGCTTTTA-3'; KDM6B, Fw $5^{\prime}-$ CCTCGAAATCCCATCACAGT-3' and Rev $5^{\prime}$ GTGCCTGTCAGATCCCAGTT-3'; SIRT1, Fw $5^{\prime}$ CTGGACAATTCCAGCCATCT-3' and Rev ${ }^{\prime}{ }^{\prime}$ GGGTGGCAACTCTGACAAAT- ${ }^{\prime}$. $18 \mathrm{~S}$ RNA was simultaneously amplified using the primers: $\mathrm{Fw} 5^{\prime}$ AAACGGCTACCACATCCAAG- $3^{\prime}$ and Rev 5'CCTCCAATGGATCCTCGTTA- $3^{\prime}$.

The real-time RT-PCR was performed using the doublestranded DNA binding dye SYBR Green PCR Master Mix (Fermentas-Thermo Scientific) on an ABI GeneAmp 7000 Sequence Detection System machine, as described by the manufacturer. The instrument, for each gene tested, obtained graphical cycle threshold values automatically. Triplicate reactions were performed for each marker and the melting curves were constructed using Dissociation Curves Software (Applied Biosystems, CA, USA), to ensure that only a single product was amplified.

The primers sequences were: $18 \mathrm{~S}$, $\mathrm{Fw} 5^{\prime}$ CCCACTCGGCACCTTACG- $3^{\prime}$ and Rev

5'-TTTCAGCCTTGCGACCATACT-3'; KDM6B, Fw $5^{\prime}$-CCTCGAAATCCCATCACAGT-3' and Rev $5^{\prime}$ GTGCCTGTCAGATCCCAGTT-3'; EZH2, Fw $5^{\prime}-$ GCCAGACTGGGAAGAAATCTG-3' and Rev $5^{\prime}$ TGTGTTGGAAAATCCAAGTCA- $3^{\prime}$.

\section{Statistical analysis}

Statistical evaluation of the differential analysis was performed by one-way ANOVA and Student's $t$-test.

\section{Acknowledgements}

This work was funded by Karo Bio Research Foundation (Huddinge, Sweden). The ERß-selective agonist KB9520 was originally provided by Karo Bio AB (Huddinge, SE). Today this ligand is owned by Oasmia Pharmaceuticals AB (Uppsala, SE).

\section{Authors' contributions}

G.P. carried out cellular and molecular studies and made substantial contributions to analysis and interpretation of data. S.N. and L.M. participated in the design and coordination of the study and drafted the manuscript. All authors have read and approved the final manuscript.

\section{Conflict of interest}

The authors declare that they have no conflict of interest.

\section{Publisher's note}

Springer Nature remains neutral with regard to jurisdictional claims in published maps and institutional affiliations.

Supplementary Information accompanies this paper at (https://doi.org/ 10.1038/s41389-018-0027-9).

Received: 23 August 2017 Revised: 21 November 2017 Accepted: 25 December 2017

Published online: 09 February 2018

\section{References}

1. Halon, A. et al. Loss of estrogen receptor beta expression correlates with shorter overall survival and lack of clinical response to chemotherapy in ovarian cancer patients. Anticancer Res. 31, 711-718 (2011).

2. Kemp, Z. \& Ledermann, J. Update on first-line treatment of advanced ovarian carcinoma. Int. J. Womens Health 5, 45-51 (2013).

3. Köbel, M. et al. Ovarian carcinoma subtypes are different diseases: implications for biomarker studies. PLoS Med. 5, e232 (2008).

4. Lalwani, N. et al. Histologic, molecular, and cytogenetic features of ovarian cancers: implications for diagnosis and treatment. Radiographics 31, 625-646 (2011).

5. Beral, V., Million Women Study Collaborators, Bull, D., Green, J. \& Reeves, G. Ovarian cancer and hormone replacement therapy in the Million Women study. Lancet 369, 1703-1710 (2007).

6. Collaborative Group on Epidemiological Studies of Ovarian Cancer1, Beral, V., Doll, R., Hermon, C., Peto, R., Reeves, G. Ovarian cancer and oral contraceptives: collaborative reanalysis of data from 45 epidemiological studies including 23,257 women with ovarian cancer and 87,303 controls. Lancet. 371, 303-314 (2008).

7. Cunat, S., Hoffmann, P. \& Pujol, P. Estrogens and epithelial ovarian cancer. Gynecol. Oncol. 94, 25-32 (2004).

8. Marchetti, C. et al. First-line treatment of advanced ovarian cancer: current research and perspectives. Expert Rev. Anticancer Ther. 10, 47-60 (2010).

9. Oronsky, B. et al. A brief review of the management of platinum-resistantplatinum-refractory ovarian cancer. Med. Oncol. 34, 103 (2017).

10. Marchetti, C., Ledermann, J. A. \& Benedetti Panici, P. An overview of early investigational therapies for chemoresistant ovarian cancer. Expert Opin. Investig. Drugs 24, 1163-1183 (2015).

11. Chan, K. K. et al. Estrogen receptor subtypes in ovarian cancer: a clinical correlation. Obstet. Gynecol. 111, 144-151 (2008).

12. Park, S. H., Cheung, L. W., Wong, A. S. \& Leung, P. C. Estrogen regulates Snail and Slug in the down-regulation of E-cadherin and induces metastatic potential of ovarian cancer cells through estrogen receptor alpha. Mol. Endocrinol. 22, 2085-2098 (2008).

13. Bossard, C. et al. Potential role of estrogen receptor beta as a tumor suppressor of epithelial ovarian cancer. PLOS ONE 7, e44787 (2012).

14. Chan, K. K. et al. Targeting estrogen receptor subtypes (ERalpha and ERbeta) with selective ER modulators in ovarian cancer. J. Endocrinol. 221, 325-336 (2014).

15. Liu, J. et al. Therapeutic utility of natural estrogen receptor beta agonists on ovarian cancer. Oncotarget 8, 50002-50014 (2017).

16. Burchfield, J. S., Li, Q., Wang, H. Y. \& Wang, R. F. JMJD3 as an epigenetic regulator in development and disease. Int. J. Biochem. Cell Biol. 67, 148-157 (2015).

17. Perrigue, P. M., Najbauer, J. \& Barciszewski, J. Histone demethylase JMJD3 at the intersection of cellular senescence and cancer. Biochim. Biophys. Acta 1865, 237-244 (2016).

18. North, B. J. \& Verdin, E. Sirtuins: Sir2-related NAD-dependent protein deacetylases. Genome Biol. 5, 224 (2004). 
19. Jang, K. Y. et al. Expression and prognostic significance of SIRT1 in ovarian epithelial tumours. Pathology 41, 366-371 (2009).

20. Mvunta, D. H. et al. Overexpression of SIRT1 is associated with poor outcomes in patients with ovarian carcinoma. Appl. Immunohistochem. Mol. Morphol. 25, 415-421 (2017).

21. Mvunta, D. H. et al. SIRT1 regulates the chemoresistance and invasiveness of ovarian carcinoma cells. Transl. Oncol. 10, 621-631 (2017)

22. Shuang, T., Wang, M., Zhou, Y. \& Shi, C. Over-expression of Sirt1 contributes to chemoresistance and indicates poor prognosis in serous epithelial ovarian cancer (EOC). Med. Oncol. 32, 260 (2015).

23. Lau, K. M., Mok, S. C. \& Ho, S. M. Expression of human estrogen receptor-alpha and -beta, progesterone receptor, and androgen receptor mRNA in normal and malignant ovarian epithelial cells. Proc. Natl Acad. Sci. USA 96, 5722-5727 (1999).

24. Pinton, G. et al. Agonist activation of estrogen receptor beta (ERbeta) sensitizes malignant pleural mesothelioma cells to cisplatin cytotoxicity. Mol. Cancer 13, 227 (2014).

25. Manente, A. G. et al. KDM6B histone demethylase is an epigenetic regulator of estrogen receptor beta expression in human pleural mesothelioma. Epigenomics 8, 1227-1238 (2016).

26. Schüler-Toprak, S., Moehle, C., Skrzypczak, M., Ortmann, O. \& Treeck, O. Effect of estrogen receptor beta agonists on proliferation and gene expression of ovarian cancer cells. BMC Cancer 17, 319 (2017).

27. Treeck, O. et al. Estrogen receptor \{beta\}1 exerts antitumoral effects on SK-OV3 ovarian cancer cells. J. Endocrinol. 193, 421-433 (2007).

28. Helguero, L. A., Faulds, M. H., Gustafsson, J. A. \& Haldosén, L. A. Estrogen receptors alfa (ERalpha) and beta (ERbeta) differentially regulate proliferation and apoptosis of the normal murine mammary epithelial cell line HC11. Oncogene 24, 6605-6616 (2005).

29. Chang, E. C. et al. Estrogen receptors alpha and beta as determinants of gene expression: influence of ligand, dose, and chromatin binding. Mol. Endocrinol. 22, 1032-1043 (2008).

30. Williams, C., Edvardsson, K., Lewandowski, S. A., Ström, A. \& Gustafsson, J. A. A genome-wide study of the repressive effects of estrogen receptor beta on estrogen receptor alpha signaling in breast cancer cells. Oncogene $\mathbf{2 7}$ 1019-1032 (2008)

31. Matthews, J. et al. Estrogen receptor (ER) beta modulates ERalpha-mediated transcriptional activation by altering the recruitment of c-Fos and c-Jun to estrogen-responsive promoters. Mol. Endocrinol. 20, 534-543 (2006).

32. Bouras, T. et al. SIRT1 deacetylation and repression of p300 involves lysine residues 1020/1024 within the cell cycle regulatory domain 1. J. Biol. Chem. 280, 10264-10276 (2005)

33. Kim, S. H., Kang, H. J., Na, H. \& Lee, M. O. Trichostatin A enhances acetylation as well as protein stability of ERalpha through induction of p300 protein. Breast Cancer Res. 12, R22 (2010)

34. Kim, M. Y., Woo, E. M., Chong, Y. T., Homenko, D. R. \& Kraus, W. L. Acetylation of estrogen receptor alpha by p300 at lysines 266 and 268 enhances the deoxyribonucleic acid binding and transactivation activities of the receptor. Mol. Endocrinol. 20, 1479-1493 (2006).

35. Noritsugu, K., Ito, A., Nakao, Y. \& Yoshida, M. Identification of zinc finger transcription factor EGR2 as a novel acetylated protein. Biochem. Biophys. Res. 489, 455-459 (2017). 